\title{
COMPARISON OF EFFICACY OF HYPERTONIC SALINE VERSUS NORMAL SALINE IN THE TREATMENT OF CHRONIC RHINOSINUSITIS WITH THE HELP OF CT: PNS
}

\author{
Sanal Mohan Sudhakaran ${ }^{1}$, Unnikrishnan Tharayil2, Sahni Dhronan Kallidanthil ${ }^{3}$
}

${ }^{1}$ Assistant Professor, Department of ENT, Travancore Medical College.

2 Professor \& HOD, Department of ENT, Travancore Medical College.

${ }^{3}$ Associate Professor, Department of ENT, Travancore Medical College.

\section{ABSTRACT}

The present study was conducted in patients with chronic rhinosinusitis attending Department of Otorhinolaryngology both outpatient and inpatient at Travancore Medical College Hospital, Kollam, during the year 2013 to 2014. The study was conducted in fifty patients. The present prospective randomized comparative study "Comparison of efficacy of hypertonic saline versus normal saline in the treatment of chronic rhinosinusitis with the help of CT PNS." Patients were divided into two Groups A and B; Group A included twenty five patients treated with $0.9 \%$ normal saline nasal drops and the remaining twenty five patients in Group B treated with 3\% hypertonic saline nasal drops for a period of four weeks. Treatment outcome evaluated with pre- and post-treatment CT and scored according to Lund and Mackay staging system. The study showed hypertonic saline (3\%), nasal solution is more efficacious than normal saline $(0.9 \%)$ in the treatment of chronic rhinosinusitis.

\section{KEYWORDS}

Hypertonic saline, Normal Saline, Rhinosinusitis, CT Paranasal Sinuses.

HOW TO CITE THIS ARTICLE: Sudhakaran SM, Tharayil U, Kallidanthil SD. Comparison of efficacy of hypertonic saline versus normal saline in the treatment of chronic rhinosinusitis with the help of CT: PNS. J. Evolution Med. Dent. Sci. 2016;5(16):790-794,

DOI: $10.14260 /$ jemds/2016/183

\section{INTRODUCTION}

Rhinosinusitis refers to inflammation of the nasal cavities and sinuses. Rhinosinusitis is a frequently occurring disease with significant impact on quality of life and health care spending and economic impact in terms of absenteeism and productivity. Compared with people without chronic rhinosinusitis, those with chronic rhinosinusitis reported more days spent bedridden and more visits to family physicians, alternative healthcare providers and mental health experts. These findings underscore the significant impact of this disease on patient quality of life as well as costs of care to patients and society.

Three key elements are important for normal physiological functioning of paranasal sinuses. a) The patency of the ostium, b) Function of the ciliary apparatus, and c) The quality of secretion, impaired drainage and retention of secretion in the paranasal sinuses. This is usually caused by one or more of the following factors: a) Obstruction of the ostium, b) Reduction in the number of cilia, c) Impairment of their function, d) Overproduction of secretion, and e) Change in viscosity of secretions. So the guiding principle of management is to reverse the pathology at the ostiomeatal complex and hence new modalities of treatment have dramatically changed standards in the case of patients with rhinosinusitis. ${ }^{1}$ The common modalities of treatment for chronic rhinosinusitis include antibiotics, mucolytics, decongestants and steroids.

Long term uses of these drugs have detrimental effect both locally and systemically.

Financial or Other, Competing Interest: None.

Submission 13-01-2016, Peer Review 06-02-2016,

Acceptance 13-02-2016, Published 25-02-2016.

Corresponding Author:

Dr. Sanal Mohan Sudhakaran,

Assistant Professor,

Dept. of ENT,

Travancore Medical College, N. H. Bypass Road,

Umayanalloor P.O., Kollam-691589.

E-mail: drsanalmoh@gmail.com

DOI: $10.14260 /$ jemds/2016/183
Nasal mucociliary function became impaired in most patients who have chronic upper respiratory tract infections. There has been recent realization that non-infectious causes predispose to infectious rhinosinusitis.

This has led many others to advocate use of ancillary treatment of chronic rhinosinusitis. Otorhinolaryngologists have advocated nasal irrigations for patients with rhinosinus disease. Both surgical and non-surgical patients with a history of chronic rhinosinusitis have been encouraged to use buffered hypertonic saline nasal irrigation. Nasal irrigation aids in the clearance of secretions, debris and intranasal crusts. This is also important in the postoperative period to reduce the risk of adhesions and to promote ostiomeatal patency. Use of normal saline and hypertonic saline for nasal irrigation is an inexpensive technique that can be used alone or with other intervention for nose and paranasal sinus diseases. Since many years several different strength of hypertonic and normal saline solution have been used in patients without any documented evidence of significant change in symptomatology in sinonasal disease.

Hence, documenting efficacious ancillary therapies rather than anecdotal accounts and personal beliefs could supplement or abrogate use of various drugs. ${ }^{2}$ Improvement in mucociliary clearance is well documented with use of both normal as well as hypertonic saline. However, controversy exists regarding beneficial effects of hypertonic saline over normal saline in relieving symptoms of chronic rhinosinusitis. This study is designed to determine whether hypertonic saline nasal drops are more efficient over normal saline nasal drops in the treatment of chronic rhinosinusitis.

\section{MATERIALS AND METHODS}

Random evaluation of 50 patients presented to the OPD, Department of ENT, Travancore Medical College, Kollam, during the period 2014-15, diagnosed as chronic rhinosinusitis in the age Group 20-45 years were included in the study. They were divided into two Groups. 
Group A included twenty five patients, treated with normal saline, $0.9 \%$, ten drops, three times a day in both nostrils for a period of 4 weeks. The other twenty five cases in Group B, treated with hypertonic saline, 3\%, ten drops, three times a day in both nostrils for the same period of 4 weeks.

The diagnosis of chronic rhinosinusitis was made with two major criteria: (a) Nasal obstruction, (b) Nasal discharge/postnasal drip. Diagnosis confirmed by clinical evaluation, diagnostic nasal endoscope and CT paranasal sinuses. Treatment outcome evaluated with pre- and posttreatment CT and scored according to Lund and Mackay staging system. ${ }^{1}$ Radiological score was given separately to each sinus film, which was marked with a number by two investigators.

\begin{tabular}{|lcc|c|c|}
\hline \multicolumn{3}{|c|}{ SINUS SYSTEM } & LEFT & RIGHT \\
\hline Maxillary & & $(0,1,2)$ & & \\
Anterior & ethmoids & $(0,1,2)$ & & \\
Posterior & ethmoids & $(0,1,2)$ & & \\
Sphenoid & & $(0,1,2)$ & & \\
Frontal & $(0,1,2)$ & & \\
Ostiomeatal complex (0 or 2 only) & & & \\
\hline \multicolumn{4}{|c|}{ Table 1 } \\
\hline
\end{tabular}

0 , no abnormalities; 1 , partial opacification; 2 , total opacification. Ostiomeatal complex- 0 , not occluded; 2, occluded.

The selected patients are explained about the mode of treatment and asked to report every week for a period of 4 weeks. Both normal saline $0.9 \%$ sodium chloride solution and hypertonic solution $3 \%$ sodium chloride are commercially available and is used as solution A and B respectively. In my study a concentration of $3 \%$ saline solution is chosen because it is about the sea water concentration and is considered to be harmless. ${ }^{2}$ to avoid aerosol deposition in the lower airways, hypertonic solution is instilled as nasal drops. The drops are instilled into each nostril in sitting or lying down position with the head pulled back or hanging down to allow the secretion to flow downward from the nose without the patient breathing them in. Instillation of drops was chosen over nasal sprays to avoid breathing in solution.

The symptoms of the patients are evaluated using visual analogue score of 0 to $10(0=$ none and $10=$ most severe $)$ for nasal blockage, nasal discharge, headache, facial pain, smell disturbance and overall symptomatic improvement. This is done once in a week and at the end of the treatment. Patients are queried about the tolerance of the nasal solution by using scores $1=$ no burning sensation; $2=$ mild burning sensation $3=$ moderate burning sensation; $4=$ severe burning sensation.

\section{Inclusion Criteria}

1. Age, 20-45 years.

2. Sex, both sexes.

3. Patients with nasal obstruction and nasal discharge/post nasal drip $>3$ months.

4. Patients treated with antibiotics, $\beta 2$ agonists, topical steroids and systemic steroids are included in the study provided the treatment is stopped one month prior to study.

5. CT paranasal sinuses with score 4 are included in the study.

\section{Exclusion Criteria}

1. Patients with fever, treated with antibiotics or steroids during the study.
2. Patients with any anatomical defect or mucocele that obstruct the sinuses.

3. Post-operative patients.

4. Post-traumatic patients.

\section{RESULTS}

\begin{tabular}{|c|c|c|c|c|}
\hline VAS a & Group & $\begin{array}{c}\text { No. of } \\
\text { Patients }\end{array}$ & $\begin{array}{c}\text { Mean } \pm \text { Standard } \\
\text { Deviation }\end{array}$ & $\begin{array}{c}P \\
\text { value }\end{array}$ \\
\hline \multirow{2}{*}{$\begin{array}{c}1^{\text {st }} \\
\text { week }\end{array}$} & A & 23 & $8.26 \pm 0.54$ & \multirow{2}{*}{0.108} \\
\hline & B & 23 & $7.96 \pm 0.71$ & \\
\hline \multirow{2}{*}{$\begin{array}{c}2^{\text {nd }} \\
\text { week }\end{array}$} & A & 23 & $6.26 \pm 0.86$ & \multirow{2}{*}{0.008} \\
\hline & $\mathrm{B}$ & 23 & $5.57 \pm 0.84$ & \\
\hline \multirow{2}{*}{$\begin{array}{c}3^{\text {rd }} \\
\text { week }\end{array}$} & $\mathrm{A}$ & 23 & $4.04 \pm 1.19$ & \multirow{2}{*}{$<0.0005$} \\
\hline & $\mathrm{B}$ & 23 & $2.78 \pm 0.74$ & \\
\hline \multirow{2}{*}{$\begin{array}{c}4^{\text {th }} \\
\text { week }\end{array}$} & A & 23 & $2.09 \pm 1.12$ & \multirow{2}{*}{$<0.0005$} \\
\hline & B & 23 & $0.35 \pm 0.65$ & \\
\hline
\end{tabular}

Patients in Group B had significant improvement in nasal blockage by the end of fourth week when compared to Group A.

\begin{tabular}{|c|c|c|c|c|}
\hline VAS b & Group & $\begin{array}{c}\text { No. of } \\
\text { Patients }\end{array}$ & $\begin{array}{c}\text { Mean } \pm \\
\text { Standard } \\
\text { Deviation }\end{array}$ & $\begin{array}{c}P \\
\text { value }\end{array}$ \\
\hline \multirow{2}{*}{$1^{\text {st }}$ week } & $\mathrm{A}$ & 23 & $8.04 \pm 0.64$ & \multirow{2}{*}{0.206} \\
\hline & B & 23 & $7.78 \pm 0.74$ & \\
\hline \multirow{2}{*}{$2^{\text {nd }}$ week } & $\mathrm{A}$ & 23 & $6.13 \pm 1.06$ & \multirow{2}{*}{0.008} \\
\hline & B & 23 & $5.30 \pm 0.97$ & \\
\hline \multirow{2}{*}{$3^{\text {rd }}$ week } & $\mathrm{A}$ & 23 & $4.04 \pm 1.19$ & \multirow{2}{*}{$<0.0005$} \\
\hline & $\mathrm{B}$ & 23 & $2.78 \pm 0.74$ & \\
\hline \multirow{2}{*}{$4^{\text {th }}$ week } & $\mathrm{A}$ & 23 & $2.04 \pm 1.26$ & \multirow{2}{*}{$<0.0005$} \\
\hline & $\mathrm{B}$ & 23 & $0.35 \pm 0.65$ & \\
\hline & $\begin{array}{r}\text { Table } 3 \\
\text { discharge }\end{array}$ & $\begin{array}{l}\text { eatment } \\
\text { (S b) in } G\end{array}$ & $\begin{array}{l}\text { lysis of nas } \\
\text { p A and Gro }\end{array}$ & \\
\hline
\end{tabular}

Patients reported clear nasal secretions and reduction in quantity of secretions by the end of fourth week in both the Groups. But when compared with Group A, Group B showed significant improvement by the end of 4 th week.

\begin{tabular}{|c|c|c|c|c|}
\hline VAS c & Group & $\begin{array}{c}\text { No. of } \\
\text { Patients }\end{array}$ & $\begin{array}{c}\text { Mean } \pm \\
\text { Standard } \\
\text { Deviation }\end{array}$ & $P$ value \\
\hline \multirow{2}{*}{$\begin{array}{c}1^{\text {st }} \\
\text { week }\end{array}$} & $\mathrm{A}$ & 22 & $6.13 \pm 1.58$ & \multirow{2}{*}{0.281} \\
\hline & $\mathrm{B}$ & 23 & $5.74 \pm 0.69$ & \\
\hline \multirow{2}{*}{$\begin{array}{c}2^{\text {nd }} \\
\text { week }\end{array}$} & $\mathrm{A}$ & 22 & $4.22 \pm 1.20$ & \multirow{2}{*}{0.077} \\
\hline & $\mathrm{B}$ & 23 & $3.65 \pm 0.88$ & \\
\hline \multirow{2}{*}{$\begin{array}{c}3^{\text {rd }} \\
\text { week }\end{array}$} & $\mathrm{A}$ & 22 & $2.57 \pm 0.90$ & \multirow{2}{*}{0.001} \\
\hline & $\mathrm{B}$ & 23 & $1.65 \pm 0.78$ & \\
\hline \multirow{2}{*}{$\begin{array}{c}4^{\text {th }} \\
\text { week }\end{array}$} & A & 22 & $1.00 \pm 0.80$ & \multirow{2}{*}{$<0.0005$} \\
\hline & $\mathrm{B}$ & 23 & $0.00 \pm 0.00$ & \\
\hline & Tahle & $\begin{array}{l}\text { reatme } \\
\text { c) in } \mathrm{Gr}\end{array}$ & $\begin{array}{l}\text { lysis of hea } \\
\text { and Group }\end{array}$ & \\
\hline
\end{tabular}

Patient reported relief of headache in both the Groups, but when compared with Group A, Group B showed significant improvement by the end of 4 th week.

\begin{tabular}{|c|c|c|c|c|}
\hline VAS d & Group & $\begin{array}{c}\text { No. of } \\
\text { Patients }\end{array}$ & $\begin{array}{c}\text { Mean } \pm \\
\text { Standard } \\
\text { Deviation }\end{array}$ & $\begin{array}{c}\mathbf{P} \\
\text { value }\end{array}$ \\
\hline \multirow{2}{*}{$1^{\text {st }}$ week } & A & 5 & $1.17 \pm 2.29$ & \multirow{2}{*}{0.713} \\
\hline & $\mathrm{B}$ & 6 & $1.43 \pm 2.48$ & \\
\hline \multirow{2}{*}{$2^{\text {nd }}$ week } & $\mathrm{A}$ & 5 & $0.83 \pm 1.64$ & \multirow{2}{*}{1.000} \\
\hline & $\mathrm{B}$ & 6 & $0.83 \pm 1.47$ & \\
\hline \multirow{2}{*}{$3^{\text {rd }}$ week } & $\mathrm{A}$ & 5 & $0.39 \pm 0.84$ & \multirow{2}{*}{0.402} \\
\hline & $\mathrm{B}$ & 6 & $0.22 \pm 0.52$ & \\
\hline \multirow{2}{*}{$4^{\text {th }}$ week } & A & 5 & $0.04 \pm 0.21$ & \multirow{2}{*}{0.323} \\
\hline & $\mathrm{B}$ & 6 & $0.00 \pm 0.00$ & \\
\hline & $\begin{array}{l}\text { ble 5: } \\
\text { in (VA }\end{array}$ & $\begin{array}{l}\text { ment and } \\
\text { Group }\end{array}$ & $\begin{array}{l}s \text { of facial } \\
\text { Group B }\end{array}$ & \\
\hline
\end{tabular}


It was observed that facial pain almost subsided in both the Groups by the end of 4th week of treatment and it was statistically not significant when compared between the two Groups.

\begin{tabular}{|c|c|c|c|c|}
\hline VAS e & Group & $\begin{array}{c}\text { No. of } \\
\text { Patients }\end{array}$ & $\begin{array}{c}\text { Mean } \pm \\
\text { Standard } \\
\text { Deviation }\end{array}$ & P value \\
\hline \multirow{2}{*}{$1^{\text {st }}$ week } & A & 13 & $4.39 \pm 3.99$ & \multirow{2}{*}{0.142} \\
\hline & $\mathrm{B}$ & 18 & $6.00 \pm 3.28$ & \\
\hline \multirow{2}{*}{$2^{\text {nd }}$ week } & A & 13 & $3.22 \pm 2.97$ & \multirow[b]{2}{*}{0.179} \\
\hline & B & 18 & $4.30 \pm 2.40$ & \\
\hline \multirow{2}{*}{$3^{\text {rd }}$ week } & A & 13 & $1.96 \pm 1.87$ & \multirow{2}{*}{0.718} \\
\hline & B & 18 & $2.13 \pm 1.32$ & \\
\hline \multirow{2}{*}{$4^{\text {th }}$ week } & A & 13 & $0.83 \pm 0.89$ & \multirow{2}{*}{0.002} \\
\hline & B & 18 & $0.17 \pm 0.39$ & \\
\hline
\end{tabular}

Both the Groups showed improvement in loss of smell, but Group B showed significant improvement.

\begin{tabular}{|c|c|c|c|c|}
\hline VAS $\mathrm{f}$ & Group & $\begin{array}{c}\text { No. of } \\
\text { Patients }\end{array}$ & $\begin{array}{c}\text { Mean } \pm \\
\text { Standard } \\
\text { Deviation }\end{array}$ & $\begin{array}{c}P \\
\text { value }\end{array}$ \\
\hline \multirow[b]{2}{*}{$1^{\text {st }}$ week } & A & 23 & $7.83 \pm 0.49$ & \multirow[b]{2}{*}{0.571} \\
\hline & B & 23 & $7.74 \pm 0.54$ & \\
\hline \multirow{2}{*}{$2^{\text {nd }}$ week } & A & 23 & $5.87 \pm 0.69$ & \multirow{2}{*}{0.016} \\
\hline & B & 23 & $5.35 \pm 0.71$ & \\
\hline \multirow{2}{*}{$3^{\text {rd }}$ week } & A & 23 & $3.87 \pm 0.81$ & \multirow{2}{*}{$<0.0005$} \\
\hline & B & 23 & $2.83 \pm 0.65$ & \\
\hline \multirow{2}{*}{$4^{\text {th }}$ week } & A & 23 & $2.00 \pm 0.85$ & \multirow{2}{*}{$<0.0005$} \\
\hline & B & 23 & $0.57 \pm 0.73$ & \\
\hline
\end{tabular}

In our study both the Groups showed overall improvement in symptoms but when compared, Group B showed significant improvement.
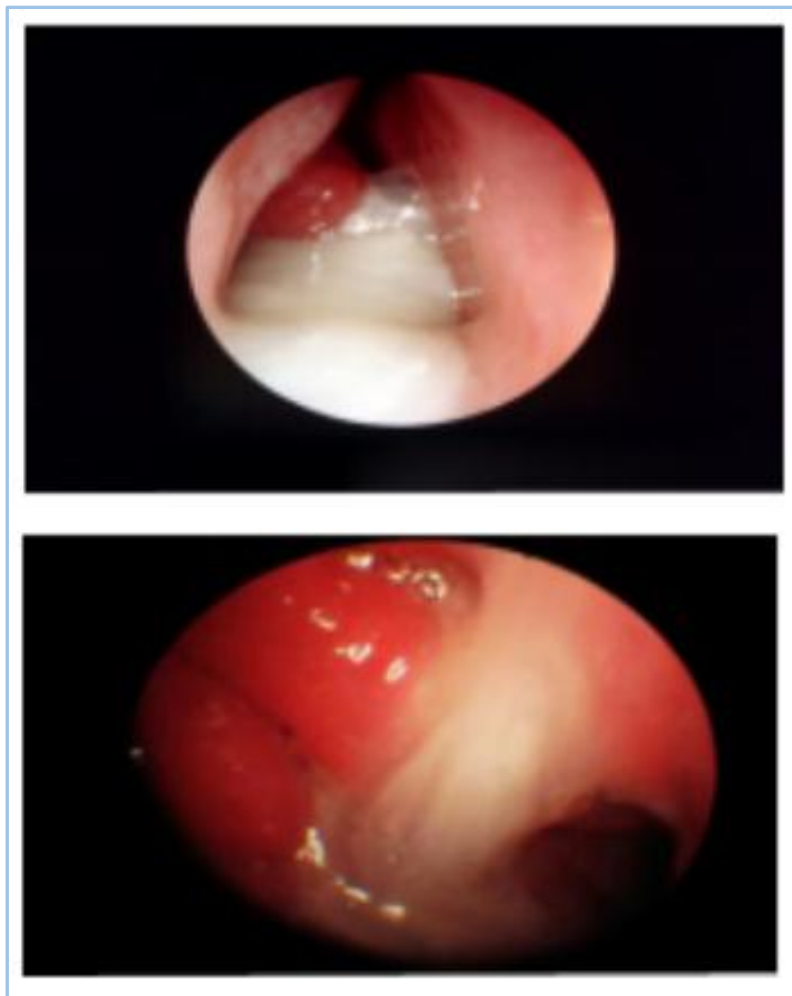

Fig. 1: Diagnostic Nasal Endoscopy showing Mucopurulent Discharge in Chronic Rhinosinusitis

\section{DISCUSSION}

Chronic rhinosinusitis affects all age Groups and is the cause of significant morbidity. The present prospective randomized comparative study "Comparison of efficacy of hypertonic saline versus normal saline in the treatment of chronic rhinosinusitis with the help of CT-PNS" was conducted in patients who attended our Department of E.N.T., Travancore Medical College, Kollam. Fifty adult patients in the age Group of 20-45 years were included in the study and were divided into two Groups randomly.

Group A included twenty five patients treated with $0.9 \%$ normal saline nasal drops (Solution A) and the remaining twenty five patients in Group B treated with 3\% hypertonic saline nasal drops (Solution B) for a period of four weeks.

In my study forty six patients completed the treatment, out of which $43.48 \%$ were in the age Group of $20-30$ years, $45.65 \%$ in the age $30-40$ years and $10.87 \%$ in the age of $40-45$ years. Mean age in Group A was 30.04 \pm 8.42 years and that in Group B was 33.00 \pm 6.50 .

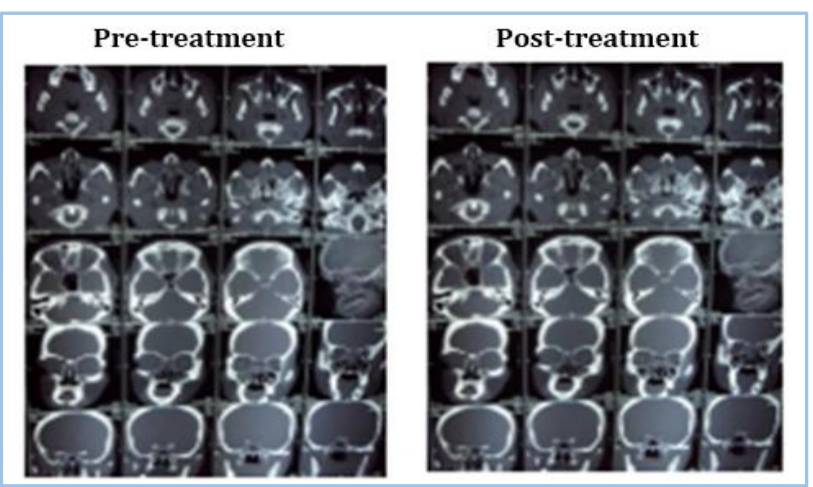

Fig. 2: Showing No Significant Radiological Improvement after Treatment with Normal Saline (0.9\%) Nasal Drops

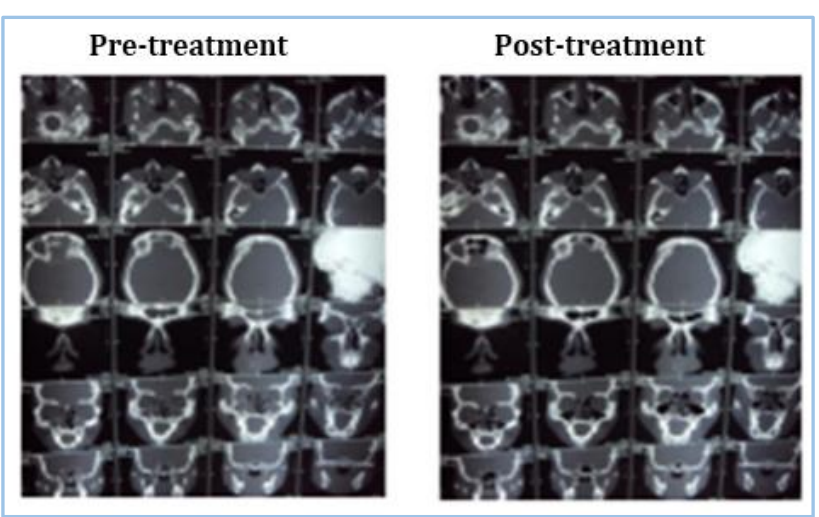

Fig. 3: Showing Significant Radiological Improvement after Treatment with Hypertonic saline (3\%) Nasal Drops

In my study, out of fifty patients $8 \%$ failed to turn up for followup. Chronic rhinosinusitis affects more commonly females. In my study also a female preponderance was noticed. The study includes sixteen males and thirty females. Females constituted $65.22 \%$ and males $34.78 \%$.

In my study almost all patients had nasal blockage, nasal discharge and headache. Few patients had facial pain and loss of smell. Each symptom was scored by Visual Analogue Scale (VAS) and compared with mean from the end of first and fourth week. A significant improvement in nasal blockage was observed in both Groups, but more significant in Group B. In Group A, mean difference from first to fourth week was from 
$8.26 \pm 0.54$ to $2.09 \pm 1.12$ and that of Group B was from $7.96 \pm 0.71$ to $0.35 \pm 0.65$.

All the forty six patients in my study Group reported improvement in nasal secretions score. However, a significant improvement in Group B was noted, as nasal secretions/post nasal drip disappeared or became clear in most of the patients.

In Group A, a mean difference from first week to fourth week was from $8.04 \pm 0.64$ to $2.04 \pm 1.26$ and that of Group B was from $7.78 \pm 0.74$ to $0.35 \pm 0.65$. Also most of the patients in both Groups reported relief of headache, but in Group B relief from headache was much earlier and significant when compared to Group A.

In Group $A$, a mean difference from first week to fourth week was from $6.13 \pm 1.58$ to $1.00 \pm 0.80$ and that for Group B was from $5.74 \pm 0.69$ to $0.00 \pm 0.00$. Only eleven patients in my study complained of facial pain, $10.87 \%$ from Group A and $13.04 \%$ from Group B. In Group A, a mean difference from first week to fourth week was from $1.17 \pm 2.29$ to $0.04 \pm 0.21$ and that of Group B was from $1.43 \pm 2.48$ to $0.00 \pm 0.00$ and it was insignificant.

We observed that sense of smell improved with treatment in both the Groups and had significant change in the Group B at the end of the study. Loss of smell was reported by thirteen patients in Group A and eighteen patients in Group B. In Group A, a mean difference from first week to fourth week was from $4.39 \pm 3.99$ to $0.83 \pm 0.89$ and that of Group B was from $6.00 \pm 3.28$ to $0.17 \pm 0.39$. Overall symptomatic improvement in Group A, a mean difference from first week to fourth week was from $7.83 \pm 0.49$ to $2.00 \pm 0.85$ and that of Group B was from $7.74 \pm 0.54$ to $0.57 \pm 0.73$. Statistically significant overall improvement in patients treated with hypertonic saline in Group B was observed in our study.

Radiological analysis in Group A showed that there were three patients with right-sided pansinusitis; nine patients with left-sided pansinusitis and rest eleven patients with bilateral pansinusitis. In Group B, nine patients with right-sided pansinusitis; four patients with left-sided pansinusitis and rest ten patients with bilateral pansinusitis. The randomization of cases was statistically insignificant. Analysis of pre-treatment and post-treatment radiological mean value revealed highly significant improvement in Group B (From 12.35 \pm 4.48 to $5.52 \pm 1.73$ ) compared to Group A (From $13.74 \pm 4.77$ to $12.30 \pm 4.33)$.

Tolerance to $0.9 \%$ normal saline solution used as solution A in Group A and 3\% hypertonic saline nasal solution used as solution B in Group B, showed moderate burning sensation in $4.3 \%$ of patients in Group A and $8.7 \%$ in Group B. Whereas mild burning sensation was reported in $30.4 \%$ in Group A and $56.5 \%$ in Group B respectively. No burning sensation reported $65.2 \%$ in Group A and 34.8\% in Group B. When comparing both Groups, it was statistically insignificant and both solution was well tolerated by both the Groups.

The usual modalities of treatment include antibiotics, decongestants, mucolytics and steroids. Long term use of these drugs has detrimental effects both locally and systemically. Hypertonic saline has been advocated since Vedic times, as an adjunctive care for rhinosinusitis. In Hatha Yoga, "Jala neti" is described as nasal cleansing technique for sinonasal diseases. ${ }^{3}$

My study shows hypertonic saline nasal solutions reduces symptoms of chronic rhinosinusitis and its efficacy over normal saline nasal solution. In my study, I preferred 3\% saline solution because it is about the concentration of sea water and was considered harmless and better tolerated by the patients, even children. ${ }^{4}$ It has been hypothesized that it improves mucociliary function..$^{5-7}$ decreases mucosal edema and inflammatory mediators. ${ }^{8}$ and mechanically clears inspissated mucus. 9,10

In addition, hypertonic saline is said to have a mild vasoconstrictive effect. ${ }^{11}$ and antibacterial property. ${ }^{12}$ Osmotic equilibrium was reached within 3 minutes and there was no injury to the epithelial or endothelial barriers of the lung. ${ }^{13}$ Intrinsic ciliary beat frequency and ultrastructure are not inherently impaired in chronic sinusitis, because impaired ciliary function caused by chronic sinusitis reverses to normal after removal and cleansing the mucosa of infected mucous and other material. ${ }^{14}$ It appears that respiratory ciliated cells have a functional reserve that permits them to auto regulate their mechanical output in response to changing respiratory mucus viscosity. ${ }^{15}$ The dynamic viscoelastic properties of nasal mucosa determined by oscillary rheometry has revealed significant improvement in elasticity after repeated antral lavages in chronic sinusitis. ${ }^{16}$ It is hypothesized that it improves mucociliary function, decreases mucosal oedema and inflammatory mediators and mechanically clears inspissated mucus. In addition, hypertonic saline said to have mild vasoconstrictive effect and antibacterial property.

From the above discussion of the result and analysis, it can be inferred that hypertonic saline (3\%) and normal saline $(0.9 \%)$ has a clear role in the treatment of chronic rhinosinusitis but hypertonic saline brings more symptomatic improvement and radiological changes and proves its efficacy over normal saline.

Moreover hypertonic saline is well tolerated by the patients. Treatment of patients with hypertonic saline is a simple solution to a common and expensive clinical problem and improves the quality of life.

\section{CONCLUSION}

The study showed hypertonic saline (3\%) nasal solution is more efficacious than normal saline (0.9\%) in the treatment of chronic rhinosinusitis. Patients show (i) Improvement in nasal blockage, (ii) Nasal secretions-post nasal drip disappeared or becomes clear, (iii) Relief of headache, (iv) Improvement of smell in patients treated with hypertonic saline when compared with normal saline. Hypertonic saline nasal solution is well tolerated by the patients with chronic rhinosinusitis and improves the quality of life.

\section{REFERENCES}

1. VAS by Lund VJ and Mackay IS. Surgical management of sinusitis. Scott Brown's Otolaryngology, 7th edition, 2008; Edward Arnold publishers, Page 1490; Table 117.9.

2. Shoseyov D, Bibi H, Shai P, et al. "Treatment with hypertonic saline versus normal saline nasal wash of pediatric chronic sinusitis." Journal of Allergy and Clinical Immunology, Vol. 101, No. 5, 1998, pp. 602-605. Doi: 10.1016/S0091-6749(98)70166-6.

3. Instruction Manual and General Information on Yogic Saline Nasal Cleansing Technique. The Jala-neti Booklet [cited 2005 Dec 30]: [41 screens]. Available from: URL: http://www.yogaage.com.

4. David Shoseyov MD, Haim Bibi MD, Pintov Shai MD, et al. Treatment with hypertonic saline versus normal saline wash of pediatrics chronic sinusitis. The Journal of Allergy and Clinical Immunology 1998;101:602-605. 
5. Band BC, Mukherjee AL and Bang FB. "Human Nasal Mucous Flow Rates." The Johns Hopkins Medical Journal, Vol. 121, No. 1, 1967, pp. 38-48.

6. Grossan M. "A Device for Nasal Irrigation." ANL, Vol. 3, 1976, pp. 65-70.

7. Majima Y, Sakakura Y, Matsubara T, et al. "Mucociliary Clearance in Chronic Sinusitis: Related Human Nasal Clearance and in Vitro Bullfrog Palate Clearance." Biorheology, Vol. 20, No. 2, 1983, pp. 251-262.

8. Georgitis JW. "Nasal Hyperthermia and Simple Irrigation for Perennial Rhinitis." Chest, Vol. 106, No. 5, 1994, pp. 1487-1491. Doi: 10.1378/chest.106.5.1487.

9. Dulfano MJ, Adler K and Wooten O. "Primary properties of Sputum. IV. Effects of 100 Percent Humidity and Water Mist." American Review of Respiratory Disease, Vol. 107, No. 1, 1973, pp. 130-132.

10. Rossman CM, Lee RM, Forrest JB, et al. "Nasal Ciliary Ultrastructure and Function in Patients with Primary Ciliary Dyskinesia Compared with that in Normal Subjects and in Subjects with Various Respiratory Diseases." American Review of Respiratory Disease, Vol. 129, No. 1, 1984, pp. 161-170.

11. Manning SC. "Pediatric Sinusitis." Otolaryngologic Clinics of North America. Vol. 26, No. 4, 1993, pp. 623-638.
12. Mangete EDO, West D and Blankson CD. "Hypertonic Saline Solution for Wound Dressing (Letter)." The Lancet, Vol. 340, No. 8831, 1992, pp. 1351. Doi: 10.1016/01406736(92)92533-L.

13. Folkesson HG, Kheradmand F and Matthay MA. "The Effect of Salt Water on Alveolar Epithelial Barrier Function." American Journal of Respiratory and Critical Care Medicine, Vol. 150, No. 6, 1994, pp. 1555-1563. Doi: 10.1164/ajrccm.150.6.7952614.

14. Mangete EDO, West D and Blankson CD. "Hypertonic Saline Solution for Wound Dressing (Letter)." The Lancet, Vol. 340, No. 8831, 1992, pp. 1351. Doi: 10.1016/01406736(92)92533-L.

15. Johnson NT, Villalon M, Royce FH, et al. "Auto regulation of Beat Frequency in Respiratory Ciliated Cells demonstrated by Viscous Loading." American Review of Respiratory Disease, Vol. 144, No. 5, 1991, pp. 1091-1094. Doi: 10.1164/ajrccm/144.5.1091.

16. Hirata K. "Dynamic Viscoelasticity of Nasal Mucus from Children with Chronic Sinusitis." Mie Medical Journal, Vol. 34, 1985, pp. 205-219. 